\title{
Major obstetric haemorrhage in Metro East, Cape Town, South Africa: a population- based cohort study using the maternal near-miss approach
}

Anke Heitkamp ${ }^{1,2^{*}}$, Simcha Lot Aronson ${ }^{3}$, Thomas van den Akker ${ }^{3,4}$, Linda Vollmer ${ }^{1}$, Stefan Gebhardt ${ }^{1}$, Jos van Roosmalen ${ }^{3,4}$, Johanna I. de Vries ${ }^{2}$ and Gerhard Theron ${ }^{1}$

\begin{abstract}
Background: Major obstetric haemorrhage is a leading cause of maternal mortality and accounts for one-third of maternal deaths in of Africa. This study aimed to assess the population-based incidence, causes, management and outcomes of major obstetric haemorrhage and risk factors associated with poor maternal outcome.

Methods: Women with major obstetric haemorrhage who met the WHO maternal near-miss criteria or died in the Metro East region, Cape Town, South Africa, were evaluated from November 2014-November 2015. Major obstetric haemorrhage was defined as haemorrhage in pregnancies of at least 20 weeks' gestation or occurring up to 42 days after birth, and leading to hysterectomy, hypovolaemic shock or blood transfusion of $\geq 5$ units of Packed Red Blood Cells. A logistic regression model was used to analyse associations with poor outcome, defined as major obstetric haemorrhage leading to massive transfusion of $\geq 8$ units of packed red blood cells, hysterectomy or death.

Results: The incidence of major obstetric haemorrhage was 3/1000 births, and the incidence of massive transfusion was 4/10.000 births in the Metro East region (32.862 births occurred during the studied time period). Leading causes of haemorrhage were placental abruption 45/119 (37.8\%), complications of caesarean section 29/119 (24.4\%) and uterine atony 13/119 (10.9\%). Therapeutic oxytocin was administered in 98/119 (82.4\%) women and hysterectomy performed in 33/119 (27.7\%). The median numbers of packed red blood cells and units of Fresh Frozen Plasma transfused were 6 (interquartile range 4-7) and 3 (interquartile range 2-4), ratio 1.7:1. Caesarean section was independently associated with poor maternal outcome: adjusted OR 4.01 [95\% Cl 1.58, 10.14].

Conclusions: Assessment of major obstetric haemorrhage using the Maternal Near Miss approach revealed that placental abruption and complications of caesarean section were the major causes of major obstetric haemorrhage. Caesarean section was associated with poor outcome.
\end{abstract}

Keywords: Maternal near-miss, Major obstetric haemorrhage, Placental abruption, Caesarean section

\footnotetext{
*Correspondence: a.heitkamp@amsterdamumc.nl; ankedok@hotmail.com 'Department of Obstetrics and Gynaecology, Stellenbosch University and Tygerberg Academic Hospital, Francie van Zijl Avenue, Cape Town 7505, South Africa

${ }^{2}$ Department of Obstetrics and Gynaecology, Amsterdam UMC, Vrije

Universiteit Amsterdam, Boelelaan 1117, 1081, HV, Amsterdam, the

Netherlands

Full list of author information is available at the end of the article
}

(c) The Author(s). 2020 Open Access This article is distributed under the terms of the Creative Commons Attribution 4.0 International License (http://creativecommons.org/licenses/by/4.0/), which permits unrestricted use, distribution, and reproduction in any medium, provided you give appropriate credit to the original author(s) and the source, provide a link to the Creative Commons license, and indicate if changes were made. The Creative Commons Public Domain Dedication waiver (http://creativecommons.org/publicdomain/zero/1.0/) applies to the data made available in this article, unless otherwise stated. 


\section{Background}

Major obstetric haemorrhage ( $\mathrm{MOH})$, mostly occurring postpartum, is a leading cause of maternal mortality worldwide and accounts for one-third of maternal deaths in Africa [1-3]. $\mathrm{MOH}$ is associated with severe maternal morbidity, including severe anaemia, disseminated intravascular coagulation, shock, multi-organ failure and hysterectomy, as well as long-term psychological trauma [4-7]. The disparity of maternal deaths (MD) between low/middle-income and high-income countries is evident and reflects, among others, differences in the quality of obstetric care $[2,5,8,9]$. Multiple factors contribute to these differences, including timely access to emergency interventions, availability of trained healthcare staff, financial and infrastructural factors $[5,9,10]$.

According to the 'National Committee on Confidential Enquiries into Maternal Deaths', there was a $40 \%$ increase in deaths due to $\mathrm{MOH}$ from 5 to 7 per 100.000 live births in the Western Cape province from 2011 to 2013 and 2014-2016, corresponding with two triennia reported by the 'National Committee on Confidential Enquiries into Maternal Deaths'. This increase in $\mathrm{MOH}$ in the Western Cape contrasts with the decreasing trend in $\mathrm{MOH}$-related deaths in the whole of South Africa. It was considered an important worrying epidemiological finding meriting closer investigation [11, 12].

Given the Sustainable Development Goals' aim to reduce maternal mortality, it is essential to focus on effective prevention, early diagnosis and improved clinical management of $\mathrm{MOH}$ in this region [13].

The World Health Organization (WHO) maternal near-miss (MNM) approach (2011) was developed to assess and improve obstetric care by identifying women who nearly died, but survived severe complications of pregnancy [14]. Measuring MNM in addition to MD, facilitates the investigation of a considerably larger group of women, identification of factors associated with $\mathrm{MOH}$ and evaluation of health care interventions $[14,15]$.

This study examined women with $\mathrm{MOH}$ who met the WHO organ dysfunction-based MNM criteria or died. Aims were to assess the incidence, case fatality rate, causes, management and outcomes of $\mathrm{MOH}$ as well as to examine factors associated with poor outcome, and evaluate clinical practice regarding massive blood transfusion in the Metro East region, South Africa. In the near future, this may contribute to revision of protocols in the attempt to further reduce severe maternal outcome by $\mathrm{MOH}$.

\section{Methods}

A population-based cohort study was designed to describe organ dysfunction-based MNM and MD due to major obstetric haemorrhage $(\mathrm{MOH})$ in the public health sector in the Metro East region, Cape Town,
Western Cape province, South Africa. From 1 November 2014 to 1 November 2015, women admitted to Tygerberg Hospital (TBH) were selected who met the MNM criteria or died and were suffering from $\mathrm{MOH}$ after a gestational age of 20 weeks. In South Africa and in accordance with the 'National Committee on Confidential Enquiries into Maternal Deaths', antepartum haemorrhage is defined as bleeding after 20 weeks gestation. Bleeding prior to this gestation is classified as miscarriage and early pregnancy loss and not as $\mathrm{MOH}$.

Women who met the MNM criteria at TBH, were included. TBH is a public tertiary care facility in Cape Town as well as serving as the academic hospital of the Faculty of Medicine and Health Sciences of Stellenbosch University, and the referral hospital for Metro East region. TBH has a well-equipped blood bank as well surgical and medical intensive care units. Women with pregnancy related critical care problems are treated in the Obstetric Critical Care Unit in the Department of Obstetrics.

The referral system in Metro East region is organized according to a three-tiered referral system with midwifeled units being level 0 for women with low-risk pregnancies. Depending degree of pregnancy related risk, women will be referred to district hospitals being level 1 or TBH which serves as both the second and third line referral centre.

To investigate whether there might have been missing inclusions of MNM at level 1 hospitals, a three-months survey was conducted at these institutions, revealing only three cases. These three women were not included in this study, because of difficulties in tracing the files.

Besides women who are referred from the Metro East region, TBH also receives some of the most complicated cases from other regions within the wider Western Cape province. In order to calculate accurate incidence rates, we only used data from patients referred within the Metro East region and not from the entire Western Cape Province.

MNM was defined as a woman who nearly died but survived a complication that occurred during pregnancy, childbirth or within 42 days after birth or termination of pregnancy [14]. $\mathrm{MOH}$ was defined as haemorrhage, occurring antepartum, intrapartum or postpartum, and leading to hysterectomy or blood transfusion $\geq 5$ units of Packed Red Blood Cells (RBCs) or hypovolemic shock, all of which are considered as markers of MNM [15]. Estimated volume of blood loss was not included in the definition to avoid the inaccuracies associated with visual estimation [16]. Poor maternal outcome was defined as $\mathrm{MOH}$ followed by massive blood transfusion (defined as $\geq 8$ units of RBCs) or hysterectomy or MD $[17,18]$.

Women with MNM were identified on a daily basis in the obstetric department by accessing admission and referral books by one of the investigators $(\mathrm{AH})$. 
All healthcare workers (consultants, registrars, medical officers, nurses, interns, students) were requested to inform the investigator when a woman who met the MNM criteria was admitted. Medical files of these women were screened by two investigators ( $\mathrm{LV}, \mathrm{AH})$ using the WHO organ dysfunction-based MNM criteria [14]. Women who met the definition of $\mathrm{MOH}$ as above were included in the data collection. Data collection was performed using a form specifically designed for this study including demographic details, and events before, during and after birth, up to 42 days postpartum. All the patient data were deidentified upon data collection and were collected from patient records at TBH and from the files stored electronically on the protected TBH OpenText Enterprise Content Management system. Incomplete data were attempted to be completed by searching in the stored original paper files.

TBH has protocols for postpartum haemorrhage and severe haemorrhage based on international guidelines, including recommendations on how to administer blood products. Interventions such as uterine massage and urinary catheterization were not assessed because, although these interventions are considered standard procedures, most were not recorded. Arterial embolization and cell saving equipment were not available.

\section{Statistical analyses}

Data were analysed using SPSS version 23.0 (IBM Corp. Released 2015). Descriptive data are presented as frequencies, percentages, means with standard deviations if normally distributed and medians with interquartile ranges (IQR) for skewed data. Associations of poor outcome with maternal and obstetric risk indicators were analysed in a multivariable logistic regression model using risk factors for $\mathrm{MOH}$ from the literature [19]. Cross-tabulations were used to determine whether there was a significant relationship between the explanatory variable and poor outcome. In the multivariable logistic regression model, adjusted odd ratios (OR) for risk factors related to birth were determined, corrected for antenatal risk factors. A maximum of four antenatal risk factors were included to ensure that the dataset contained at least ten women for each variable. In the multivariable logistic regression, $P$-values $<0.05$ were considered statistically significant.

The four antenatal factors were checked for collinearity. Collinearity was determined to be low if the correlation was between 0 and 0.3 .

\section{Results}

The number of women who gave birth in the Metro East region during the one-year study period was 32.862 . We identified 119 women who experienced $\mathrm{MOH}$, of which one woman died. In these 119 women, 112 singletons and 7 twins were born. The incidence of MNM with $\mathrm{MOH}$ was 3 per 1000 births, and the incidence of massive blood transfusion due to $\mathrm{MOH}$ was 4 per 10.000 births.

The majority of cases $(95 / 119(75.6 \%))$ were referred to TBH from a midwife-led unit or level 1 hospital. The mean age of included women was $28 \pm 6.5$ SD (16-43) years, and the median BMI was $26 \mathrm{~kg} / \mathrm{m}^{2}$ (range 2331 ). The median gestational age was 36 weeks (range 32-39), with 61/119 (51.2\%) women having preterm birth (Table 1).

Of all women with $\mathrm{MOH}, 46 / 119$ (38.7\%) had poor maternal outcome, of whom 25/46 (54.4\%) underwent hysterectomy, 12 received massive blood transfusions, eight had both and one woman died (Table 2).

$\mathrm{MOH}$ occurred antepartum in 12/119 (10.1\%), intrapartum in $47 / 119$ (39.5\%) and postpartum in $60 / 119$ women $(50.4 \%)$.

The leading cause of $\mathrm{MOH}$ was placental abruption in 45 women (37.8\%), followed by complications related to caesarean section (CS) (vascular and tissue related, not placenta related) in $29(24.4 \%)$ (Table 3). Characteristics and outcomes of women with placental abruption are

Table 1 Characteristics of women with $\mathrm{MOH}(n=119)$

\begin{tabular}{|c|c|}
\hline & N (\%) \\
\hline \multicolumn{2}{|c|}{ Age at delivery (years) } \\
\hline$<20$ & $11(9.2)$ \\
\hline $20-34$ & $88(73.9)$ \\
\hline $35-39$ & $10(8.4)$ \\
\hline$\geq 40$ & $10(8.4)$ \\
\hline \multicolumn{2}{|l|}{ BMI } \\
\hline$<18$ & $2(1.7)$ \\
\hline $18-24$ & $36(30.3)$ \\
\hline $25-29$ & $31(26.1)$ \\
\hline $30-34$ & $12(10.1)$ \\
\hline$\geq 35$ & $20(16.8)$ \\
\hline Missing data & $18(15.1)$ \\
\hline \multicolumn{2}{|l|}{ Parity $^{a}$} \\
\hline 0 & $37(31.1)$ \\
\hline $1-3$ & $76(63.9)$ \\
\hline$\geq 4$ & $6(5.0)$ \\
\hline \multicolumn{2}{|c|}{ Gestational age at delivery (weeks) } \\
\hline $20-24$ & $2(1.7)$ \\
\hline $24-31$ & $26(21.8)$ \\
\hline $32-37$ & $33(27.7)$ \\
\hline Full term (> 37) & $52(43.7)$ \\
\hline Missing data & $6(5.0)$ \\
\hline
\end{tabular}

${ }^{\mathrm{a}}$ Number of previous births 
Table 2 Obstetric outcomes of women with $\mathrm{MOH}(n=119)$

\begin{tabular}{ll}
\hline & $\mathrm{N}(\%)$ \\
\hline Mode of birth & $56(47.1)$ \\
Spontaneous vaginal birth & $4(3.3)$ \\
Instrumental & $58(48.7)$ \\
Caesarean section & $1(0.8)$ \\
Laparotomy for ectopic pregnancy & \\
Maternal outcome & $1(0.8)$ \\
Maternal death & $46(38.7)$ \\
Poor outcome MOH a & $1(0.8)$ \\
Case fatality rate & \\
Neonatal outcome ( $n=126)$ & $61(48.8)$ \\
Live births & $58(46.0)$ \\
Stillbirths & $3(2.4)$ \\
Neonatal deaths & $4(3.2)$ \\
Missing data &
\end{tabular}

or death

shown in Table 4. The mean age (SD) was $25.7 \pm 5.9$ SD years and the median gestational age was 33 (29-36) weeks. No cocaine use or multiple pregnancies were reported in these 45 women.

The majority of women (26/45 (57.8\%)) presented intrapartum, mostly presenting with disseminated intravascular coagulation or shock, and gave birth some hours later). Ten women $(22.2 \%)$ presented antepartum and $9(20 \%)$ women presented postpartum.

Interventions in the management of $\mathrm{MOH}$ are presented in Table 5. For every woman who had MNM due to $\mathrm{MOH}$, interventions were identified which were performed to

Table 3 Primary causes of obstetric haemorrhage $(n=119)$

\begin{tabular}{ll}
\hline $\begin{array}{l}\text { Placental abnormalities } \\
\quad \text { wbruption }\end{array}$ & \\
$\quad$ with hypertension & \\
$\quad$ without hypertension & $35(29.4)$ \\
Retained placenta & $10(8.4)$ \\
Placenta previa & $11(9.2)$ \\
Abnormally invasive placenta & $5(4.2)$ \\
Operative complications & $5(4.2)$ \\
$\quad$ during CS & \\
$\quad$ after CS & $10(8.4)$ \\
Uterine Atony & $19(16)$ \\
Perineal trauma & $13(10.9)$ \\
Uterine rupture & 6 \\
Uterine inversion & $3(2.5)$ \\
Subcapsular liver haematoma & $1(0.8)$ \\
aCS caesarean section & $1(0.8)$ \\
\hline
\end{tabular}

${ }^{\mathrm{a} C S}$ caesarean section
Table 4 Characteristics and outcomes of women with placental abruption as primary cause of $\mathrm{MOH}[20](n=45)$

\begin{tabular}{|c|c|}
\hline & N (\%) \\
\hline \multicolumn{2}{|l|}{ Maternal risk factors } \\
\hline Primigravida & $15(33.3)$ \\
\hline Parity $\geq 4$ & $2(4.4)$ \\
\hline Alcohol $^{a}$ & $7(2)$ \\
\hline Smoking ${ }^{a}$ & $11(25)$ \\
\hline Anaemia & $2(4.4)$ \\
\hline \multicolumn{2}{|l|}{ Risk factors from past obstetrics history } \\
\hline Hypertensive disease & $12(26.7)$ \\
\hline Caesarean section & $8(17.8)$ \\
\hline Placental abruption & $3(6.7)$ \\
\hline Stillbirth & $4(8.9)$ \\
\hline Neonatal death & $3(6.7)$ \\
\hline \multicolumn{2}{|l|}{ Pregnancy-associated risk factors } \\
\hline \multicolumn{2}{|l|}{ Hypertension } \\
\hline (Pregnancy induced) hypertension & $7(15.6)$ \\
\hline Pre-eclampsia & $28(62.2)$ \\
\hline \multicolumn{2}{|l|}{ Gestation } \\
\hline $20-24$ & $5(11.1)$ \\
\hline $25-31$ & $11(24.4)$ \\
\hline $32-37$ & $19(42.2)$ \\
\hline$>37$ & $7(15.6)$ \\
\hline Missing & $3(6.7)$ \\
\hline \multicolumn{2}{|l|}{ Outcomes } \\
\hline Stillbirths & $42(95)$ \\
\hline Stillbirths on admission & $35(77.8)$ \\
\hline Fresh stillbirths & $7(15.6)$ \\
\hline$C S^{b}$ for suspected abruption (baby alive before $C S$ ) & $5(11.1)$ \\
\hline CS with stillbirth & $7(15.6)$ \\
\hline Hysterectomy & $1(2.2)$ \\
\hline Uterine rupture ${ }^{c}$ & $1(2.2)$ \\
\hline Massive transfusion $^{d}$ & $5(11.1)$ \\
\hline
\end{tabular}

control $\mathrm{MOH}$ according to local protocol. The chronological order of interventions was not retrievable. Therapeutic oxytocin was administered (prophylactic dose immediate postpartum is routine) most frequently to $98 / 119$ women $(82.4 \%)$ and was the only intervention in onequarter of all women. In addition, 34/119 (28.6\%) women received more than one uterotonic drug, and 64/119 (53.8\%) women received a mechanical or surgical intervention.

The ratio of total units of RBCs to total units of Fresh Frozen Plasma was 1.7:1 (686 units/394 units), 
Table 5 Summary of interventions in the management of $\mathrm{MOH}$ by cause ${ }^{\mathrm{a}}$

\begin{tabular}{|c|c|c|c|c|c|c|c|}
\hline & Atony & Retained & $A I P^{b}$ & Abruption & CS compli-cations ${ }^{c}$ & Total & \\
\hline & $N=13$ & $N=11$ & $N=10$ & $N=45$ & $N=29$ & $N=107$ & $\%$ \\
\hline Medical interventions & & & & & & & \\
\hline Oxytocin ${ }^{d}$ & 13 & 10 & 7 & 35 & 24 & 98 & 82.4 \\
\hline Ergometrine & 7 & 1 & 3 & 1 & 9 & 23 & 19.3 \\
\hline Misoprostol & 5 & 3 & - & 3 & 7 & 20 & 16.8 \\
\hline Tranexamic acid & 2 & 1 & 2 & 4 & 8 & 18 & 15.1 \\
\hline Prostaglandin F2-alpha & 3 & - & 1 & 1 & 3 & 8 & 6.7 \\
\hline Mechanical intervention & & & & & & & \\
\hline $\begin{array}{l}\text { Balloon or condom } \\
\text { tamponade }\end{array}$ & 6 & - & - & 1 & 1 & 10 & 8.4 \\
\hline Surgical interventions & & & & & & & \\
\hline Relook laparotomy & 5 & - & 2 & 2 & 24 & 34 & 28.6 \\
\hline Hysterectomy & 6 & 2 & 7 & 1 & 14 & 33 & 27.7 \\
\hline Removal of retained products & 3 & 10 & 2 & 4 & 3 & 23 & 19.3 \\
\hline Tear repair in theatre & - & 2 & - & 6 & 2 & 16 & 13.4 \\
\hline B-Lynch suture & 5 & - & 1 & 3 & 4 & 13 & 10.9 \\
\hline Abdominal packing & 2 & - & - & 1 & 1 & 4 & 3.4 \\
\hline Artery ligation & - & - & - & 1 & 2 & 3 & 2.5 \\
\hline Uterine rupture repair & - & - & - & - & - & 1 & 0.8 \\
\hline Uterine inversion reversal & - & - & - & - & - & 1 & 0.8 \\
\hline Management & & & & & & & \\
\hline Transfusion of blood products & 13 & 10 & 10 & 45 & 29 & 117 & 98.3 \\
\hline Massive transfusion & 1 & 1 & 2 & 5 & 9 & 20 & 16.8 \\
\hline Admission to ICU & 2 & - & 1 & 1 & 6 & 11 & 9.2 \\
\hline Missing data & & & & & & 3 & 2.5 \\
\hline
\end{tabular}

${ }^{a}$ the following causes are not displayed in this table: laceration, uterine rupture and uterine inversion

Interventions for these women are included in the total numbers

babnormally invasive placenta, including placenta previa

cbleeding related to caesarean section

$d_{\text {therapeutic dose (> } 10 \text { IE oxytocin) [21] }}$

the median number of RBC per woman was 6 (range 4-6). The ratio in the massive transfusion group was 1.8:1 (207 units/116 units), with a maximum of 41 blood products in one woman.

There were 109 women included in the multivariable logistic regression, because missing data in one of the factors meant some women had to be excluded. CS was independently associated with poor maternal outcome (OR 4.01; 95\% CI 1.58, 10.14) (Table 6). Checking for collinearity was done and low correlations between oxytocin and CS (correlation coefficient: - 0,204), induction of labour and CS (correlation coefficient-0.136) and prolonged labour and CS (correlation coefficient 0.249) were found.

\section{Discussion}

The main cause of $\mathrm{MOH}$ in our study was placental abruption. The majority of these women suffered from hypertensive disease of pregnancy and lost their child. Other frequent causes of $\mathrm{MOH}$ were complications during or after CS and uterine atony. It is remarkable that only CS was associated with poor maternal outcome. Moreover, uterine rupture was seldom encountered in the overall MNM group.

The reported incidence of $\mathrm{MOH}$ is comparable to prior published incidence rates in Pretoria, South Africa in 1998 (3 per 1000 births) and 2001 (2.8 per 1000 births) $[22,23]$. Incidence rates in high-income countries are reported to be 2.3 per 1000 births (Ireland in 2011) [24]. The WHO Multicountry Survey on Maternal and New-born Health reported incidence rates for postpartum haemorrhage of 2.9, 1.4 and 2.0 per 1000 births for low, medium and high Human Development Index countries in 2012 [5]. Yet, this survey audited severe maternal outcome (MNM and MD) due to postpartum haemorrhage only, whereas our study included 
Table 6 Univariate analysis and multivariable logistic regression of risk factors associated poor outcome (defined as massive blood transfusion, hysterectomy or death)

\begin{tabular}{|c|c|c|c|c|c|}
\hline \multirow[t]{2}{*}{ Variable } & $\begin{array}{l}\text { Poor outcome } \\
N=46\end{array}$ & $\begin{array}{l}\text { No poor outcome } \\
N=73\end{array}$ & Missing data & Crude OR [95\% Cl] & \multirow[t]{2}{*}{$\begin{array}{l}\text { Adjusted OR } \\
{[95 \% \mathrm{Cl}]}\end{array}$} \\
\hline & $N(\%)$ & N (\%) & \multicolumn{2}{|l|}{ N (\%) } & \\
\hline \multicolumn{6}{|l|}{ Antenatal } \\
\hline $\mathrm{BMI} \geq 35$ & $11(23.9)$ & $9(12.3)$ & $15(12.6)$ & $2.09[0.78,5.60]$ & - \\
\hline Age at delivery $\geq 35$ & $11(23.9)$ & $8(11.0)$ & 0 & $2.55[0.94,6.94]$ & - \\
\hline Previous c. section & 19 (41.3) & $18(24.7)$ & $3(2.5)$ & $2.15[0.97,4.78]$ & - \\
\hline Primigravida & $12(26.1)$ & $21(46.7)$ & 0 & $0.87[0.38,2.01]$ & - \\
\hline \multicolumn{6}{|l|}{ Relating to birth } \\
\hline Prolonged labour & $9(19.6)$ & $4(5.5)$ & $8(6.7)$ & $4.43[1.27,15.47]$ & $3.72[0.96,14.37]$ \\
\hline Induction of labour & $11(23.9)$ & $30(41.1)$ & $6(5.0)$ & $0.56[0.20,1.05]$ & $0.46[0.18,1.15]$ \\
\hline Oxytocin foraugmentation & $5(10.9)$ & $21(46.7)$ & $9(7.6)$ & $0.33[0.12,0.97]$ & $0.32[0.10,1.05]$ \\
\hline Caesarean section $^{a}$ & $34(73.9)$ & $24(32.9)$ & 0 & $5.79[2.55,13.13]^{* * *}$ & $4.01[1.58,10.14]^{* *}$ \\
\hline
\end{tabular}

includes caesarean section on stillbirth

** $<p 0.01$

$* * *<0.001$

antepartum and intrapartum haemorrhage as well. The incidence of postpartum haemorrhage in our study was 1.9 per 1000 births, comparable to the medium to high Human Development Index countries in the WHO survey. In general, the comparison of incidence rates of obstetric haemorrhage remains difficult, because definitions vary widely in the literature. On the other hand, the case fatality rate of $\mathrm{MOH}$ was low $(0.9 \%)$ and is consistent with the literature $[5,9]$.

The finding of placental abruption as the main cause of $\mathrm{MOH}$ in our population cannot easily be compared with other populations since most studies report antepartum haemorrhage and postpartum haemorrhage separately. The fact that uterine atony is not the most frequent cause for $\mathrm{MOH}$ is probably also because our study combines $\mathrm{MOH}$ before, during and after birth $[9,25]$. This underlines the importance of including ante- and intrapartum bleeding in studies of $\mathrm{MOH}$, rather than limiting their scope to include postpartum haemorrhage only.

Hypertensive disorders of pregnancy, placental abruption and preterm labour are pathophysiologically related with early ischemic placental disease [23, 26].

The fact that stillbirths occurred in $95 \%$ of women with abruption was not unexpected, given that the large majority presented already in shock or with symptoms of disseminated intravascular coagulation. Despite knowledge that appropriate management is to deliver stillbirths vaginally, in daily practice this is not always possible, due to acute maternal compromise requiring surgical intervention. In this study, we reported a relatively high number of CS in cases of stillbirth. Indications were maternal condition too poor for induction of labour $(3 / 7), \geq 2$ previous CS, $(1 / 7$, relative contra- indication to induce), failed induction (2/7) or ruptured uterus $(1 / 7)$.

The high number of complications during and after CS can be related to the risk factors of the women in this population. The high percentage of women with obesity $(26.9 \%$ BMI $\geq 30)$ and hypertensive disorders may complicate CS. Secondly, lack of skilled doctors can be associated with poor maternal outcome after CS [11, 27, 28]. The majority of women with MNM had low-risk pregnancies and were referred from level 1 hospitals with a high patient burden, mainly managed by medical officers and only one or two obstetricians present. Further audit may give more insight into the quality of care in this setting.

With regard to interventions in the management of $\mathrm{MOH}$, low rates of intrauterine balloon tamponade, and administration of tranexamic acid are notable. This can be explained by the fact that, in 2014, tranexamic acid was not yet included in the local guidelines. The Bakri balloon for intrauterine tamponade is a relatively expensive device and therefore rarely utilised at TBH. An alternative and more affordable device, the Ellavi balloon, was developed in South Africa, but only introduced in 2016 [29].

Even though our study suggests that the local protocol for management of $\mathrm{MOH}$ was followed, detailed information - e.g., timing, availability, and quality of the interventions and training of staff - will have to be studied in more depth in order to identify opportunities to improve management of $\mathrm{MOH}$.

Because of the increasing trend of $\mathrm{MOH}$ in the Western Cape province, recommendations from the National Committee on Confidential Enquiries into Maternal Deaths to implement guidelines that prevent $\mathrm{MOH}$, 
develop protocols for management of postpartum haemorrhage with tranexamic acid and balloon tamponade and practicing emergency drills, should be prioritised [11]. .Antenatal care and appropriate blood pressure control for hypertensive disease are, however, just as important to prevent $\mathrm{MOH}$ and abruptions.

There is no worldwide consensus on blood transfusion protocols, due to a lack of strong evidence, which is a result of discrepancy in definitions, resources and only few available randomized controlled trials [19, 30]. At TBH, the local severe haemorrhage protocol recommends that, if bleeding is not controlled after the administration of 4 units of RBCs, to infuse blood products in a ratio of 1 RBC: 1 Fresh Frozen Plasma: 1 platelets. However, our data does not reflect this recommendation meaning more individualized care was performed in practice.

We importantly adhered strictly to the criterion of $\geq 5$ RBCs for inclusion as MNM. Nonetheless, we also separately assessed massive blood transfusion since this assessment enabled comparisons with studies done in other countries. The incidence of massive transfusion was 40 per 100.000 births and is within the range of the incidence reported for the United Kingdom between 2012 and 2013 (23 per 100.000 births) and the Netherlands between 2011 and 2012 (65 per 100.000 births) [17, 18], using the same definition for massive blood transfusion.

The strength of this study is that nearly all women with $\mathrm{MOH}$ from the Metro East region were included in our database as a result of a well-organized referral system. Under reportage was investigated and, in 3 months, only three women with MNM were missed in the level 1 hospitals, meaning 12 were missed in 1 year so that only $3 \%$ of cases of MNM were underreported,. Hence, these data are considered population-based at district level. This emphasizes the need and value of a national maternal health care and perinatal data registry, which is not presently available in South Africa. Limitations of the study are that, despite our efforts of daily assessment, either incomplete documentation or inadequate data extraction from handwritten medical files could have led to information bias or non-differential misclassification. For instance, the history of hypertensive disease in pregnancy or previous pregnancies was difficult to trace and the already high prevalence of hypertensive disease of pregnancy during placental abruption can thus still be an underestimation. Although the cause of haemorrhage is likely to be multifactorial, it often involves uterine atony. Since we only documented the primary cause of haemorrhage, there might be an underestimation of the incidence of uterine atony as well.

\section{Conclusions}

Our assessment of MOH-related severe maternal outcome (MNM and MD) shows high rates of morbidity and low rates of mortality, consistent with the literature. The incidence of severe maternal outcome due to $\mathrm{MOH}$ is comparable to middle and high-income countries. The leading cause of $\mathrm{MOH}$ was placental abruption suggesting a shift towards ante- and intrapartum haemorrhage. This, in the WHO terminology (ICD-MM), illustrates the importance of tracing back the chain of events to antepartum, rather than focusing on postpartum haemorrhage only, which is what often happens in practice. Hypertensive disorders of pregnancy were present in a majority of women with placental abruptions, underlining the association between ischemic placental disease, hypertensive disorders and haemorrhage. Since caesarean section was independently associated with poor maternal outcome, careful consideration and vigilance are needed when deciding on this mode of birth. A focus on developing an evidence-based massive transfusion protocol is important to improve patient safety. Progress remains to be made regarding the reduction of morbidity rates; hence obstetric audit should be encouraged to identify opportunities to improve $\mathrm{MOH}$ management in order to avoid hysterectomy, massive transfusion and placental abruption in women with preeclampsia.

\section{Abbreviations}

BMI: Body Mass Index; CS: Caesarean Section; IQR: Inter Quartile Range; MD: Maternal Deaths; MNM: Maternal Near-Miss; MOH: Major Obstetric Haemorrhage; RBC: Red Blood Cells (RBCs; SD: Standard Deviation; TBH: Tygerberg Hospital; WHO: World Health Organization

\section{Acknowledgements}

We thank the statistician LC Bosman for her statistical advise.

\section{Authors' contributions}

$\mathrm{AH}$ and LV designed the study, with help from all other authors and identified MNM patients. AH and SA performed the literature search, collected the data, performed the statistical analyses and prepared a first draft of a manuscript, which was then edited by all authors. SG provided access to clinical data in the district. SG, TvdA, LV, JvR, JdV, GT reviewed study protocol, assisted with data analysis and interpretation, and critically commented on all drafts of the manuscript. JdV and GT provided overall guidance, revised and supervised. Each author approved the submitted version and agreed to be personally accountable for the author's own contributions and to ensure that questions related to the accuracy or integrity of any part of the work, even ones in which the author was not personally involved, are appropriately investigated, resolved, and the resolution documented in the literature.

\section{Funding}

No Funding

\section{Availability of data and materials}

The dataset used and/or analysed during the current study are available from the corresponding author on reasonable request.

\section{Ethics approval and consent to participate}

Ethical approval was obtained from the Committee for Human Research, Faculty of Health Sciences, Stellenbosch University, on 03/10/2018, Project ID: 1427, HREC Reference \#: S18/02/023. A waiver of consent from the participants was obtained from the Committee of Human Research, for the reason that this study was an audit of hospital records. Patient data were deidentified upon data collection. 


\section{Consent for publication}

Not applicable.

\section{Competing interests}

All authors declare that they have no competing interests. Thomas van den Akker and Jos Van Roosmalen are members of the editorial board (Associate Editor and Section Editor) of this journal, in order to ensure transparency, they declare that they have no competing interests.

\section{Author details}

'Department of Obstetrics and Gynaecology, Stellenbosch University and Tygerberg Academic Hospital, Francie van Zijl Avenue, Cape Town 7505, South Africa. ${ }^{2}$ Department of Obstetrics and Gynaecology, Amsterdam UMC, Vrije Universiteit Amsterdam, Boelelaan 1117, 1081, HV, Amsterdam, the Netherlands. ${ }^{3}$ Department of Obstetrics and Gynaecology, Leiden University Medical Centre, Albinusdreef 2, 2333, ZA, Leiden, the Netherlands. ${ }^{4}$ Athena Institute, Vrije Universiteit Amsterdam, Boelelaan 1085, 1081, HV, Amsterdam, the Netherlands.

Received: 6 June 2019 Accepted: 10 December 2019

Published online: 06 January 2020

\section{References}

1. Say L, Chou D, Gemmill A, et al. Global causes of maternal death: a WHO systematic analysis. Lancet Glob Health. 2014;2(6):e323-33.

2. Souza JP, Gulmezoglu AM, Vogel J, et al. Moving beyond essential interventions for reduction of maternal mortality (the WHO multicountry survey on maternal and newborn health): a cross-sectional study. Lancet. 2013;381 (9879):1747-55

3. Calvert C, Thomas SL, Ronsmans C, Wagner KS, Adler AJ, Filippi V. Identifying regional variation in the prevalence of postpartum haemorrhage: a systematic review and meta-analysis. PLoS One. 2012;7(7):e41114.

4. Sentilhes L, Gromez A, Clavier E, Resch B, Descamps P, Marpeau L. Longterm psychological impact of severe postpartum hemorrhage. Acta Obstet Gynecol Scand. 2011;90(6):615-20.

5. Sheldon WR, Blum J, Vogel JP, Souza JP, Gulmezoglu AM, Winikoff B. Postpartum haemorrhage management, risks, and maternal outcomes: findings from the World Health Organization multicountry survey on maternal and newborn health. Bjog. 2014;121(Suppl 1):5-13.

6. Royal College of Obstetricians and Gynaecologists. Postpartum Haemorrhage, Prevention and Management (Green-top Guideline No. 52). London: RCOG; 2016.

7. Royal College of Obstetricians and Gynaecologists. Antepartum Haemorrhage (Green-top Guideline No. 63). London: RCOG; 2011.

8. WHO U, UNFPA, The World Bank and the United Nations Population Division. Trends in Maternal Mortality: 1990 to 2013 Estimates by WHO, UNICEF, UNFPA, The World Bank and the United Nations Population Division. 2014

9. Maswime S, Buchmann E. A systematic review of maternal near miss and mortality due to postpartum hemorrhage. Int J Gynaecol Obstet. 2017; 137(1):1-7.

10. Kyei-Nimakoh M, Carolan-Olah M, McCann TV. Access barriers to obstetric care at health facilities in sub-Saharan Africa-a systematic review. Syst Rev. 2017:6(1):110

11. Health Department Republic of South Africa. Saving Mothers 2014-2016: Seventh triennial report on confidential enquiries into maternal deaths in South Africa:Short report. 2017

12. Pattinson RFS, Moodley J. Saving Mothers 2014: Annual report and detailed analysis of maternal deaths due to non-pregnancy related infections; 2014

13. United Nations Department of Economic and Social Affairs. The Sustainable Development Goals Report 2016.

14. World Health Organization. Evaluating the quality of care for severe pregnancy complications: the WHO near-miss approach for maternal health. 2011.

15. Say L, Souza JP, Pattinson RC. Maternal near miss--towards a standard tool for monitoring quality of maternal health care. Best Pract Res Clin Obstet Gynaecol. 2009;23(3):287-96.

16. Natrella M, Di Naro E, Loverro M, et al. The more you lose the more you miss: accuracy of postpartum blood loss visual estimation. A systematic review of the literature. J Matern Fetal Neonatal Med. 2018;31(1):106-15.

17. Green L, Knight M, Seeney FM, et al. The epidemiology and outcomes of women with postpartum haemorrhage requiring massive transfusion with eight or more units of red cells: a national cross-sectional study. BJOG. 2016; 123(13):2164-70.

18. Ramler $\mathrm{Pl}$, van den Akker $\mathrm{T}$, Henriquez $\mathrm{D}$, et al. Women receiving massive transfusion due to postpartum hemorrhage: A comparison over time between two nationwide cohort studies. Acta Obstet Gynecol Scand. 2019; 98(6):795-804

19. Dahlke JD, Mendez-Figueroa $H$, Maggio L, et al. Prevention and management of postpartum hemorrhage: a comparison of 4 national guidelines. Am J Obstet Gynecol. 2015;213(1):76.e1-10.

20. Tikkanen M. Placental abruption: epidemiology, risk factors and consequences. Acta Obstet Gynecol Scand. 2011;90(2):140-9.

21. Western Cape Clinical Guidelines Comittee, Department of Health. Western Cape, Standardised Maternal Guidelines on the Management of Postpartum Haemorrhage. 2005.

22. Cochet L, Pattinson RC, Macdonald AP. Severe acute maternal morbidity and maternal death audit--a rapid diagnostic tool for evaluating maternal care. S Afr Med J. 2003;93(9):700-2.

23. Mantel GD, Buchmann E, Rees H, Pattinson RC. Severe acute maternal morbidity: a pilot study of a definition for a near-miss. Br J Obstet Gynaecol. 1998;105(9):985-90

24. National Perinatal Epidemiology Centre. Severe maternal morbidity report 2011. Cork: NPEC; 2013.

25. Carroli G, Cuesta C, Abalos E, Gulmezoglu AM. Epidemiology of postpartum haemorrhage: a systematic review. Best Pract Res Clin Obstet Gynaecol. 2008;22(6):999-1012.

26. Parker SE, Werler MM. Epidemiology of ischemic placental disease: a focus on preterm gestations. Semin Perinatol. 2014;38(3):133-8.

27. Betran AP, Ye J, Moller AB, Zhang J, Gulmezoglu AM, Torloni MR. The increasing trend in caesarean section rates: global, regional and National Estimates: 1990-2014. PLoS One. 2016:11(2):e0148343.

28. Boerma T, Ronsmans C, Melesse DY, et al. Global epidemiology of use of and disparities in caesarean sections. Lancet. 2018;392:1341-8.

29. Theron GB. Management of postpartum hemorrhage with free-flow pressure controlled uterine balloon. Int J Gynaecol Obstet. 2018;142(3):371-3.

30. Sentilhes L, Goffinet F, Vayssiere C, Deneux-Tharaux C. Comparison of postpartum haemorrhage guidelines: discrepancies underline our lack of knowledge. Bjog. 2017;124(5):718-22.

\section{Publisher's Note}

Springer Nature remains neutral with regard to jurisdictional claims in published maps and institutional affiliations.

Ready to submit your research? Choose BMC and benefit from:

- fast, convenient online submission

- thorough peer review by experienced researchers in your field

- rapid publication on acceptance

- support for research data, including large and complex data types

- gold Open Access which fosters wider collaboration and increased citations

- maximum visibility for your research: over $100 \mathrm{M}$ website views per year

At $\mathrm{BMC}$, research is always in progress.

Learn more biomedcentral.com/submission 